\title{
Gold in Hybrid Microelectronics
}

\section{A REVIEW OF THE VANCOUVER CONFERENCE}

\author{
David T. Wall
}

Lucas Aerospace Limited, Birmingham, England

\begin{abstract}
The International Society for Hybrid Microelectronics held its 1976 International Technical Symposium in Vancouver, British Columbia, in October. The conference comprised twelve sessions on various aspects of microelectronics, with speakers from the U.S.A., Canada, Great Britain and several European countries. A number of these papers dealt with the use or the behaviour of gold in the fabrication of thin and thick film circuit assemblies.
\end{abstract}

The production of complex thin film circuits for fuel control in gas turbine engines was reviewed by V. Needham of Lucas Aerospace. The thin film circuitry approach is based upon the use of nickelchromium as the resistive material and on gold as conductor material. The processes by which these materials are deposited on to the glass or ceramic substrates were described, the sublimation of the resistor alloy and the evaporation of the gold having been superseded by R.F, diode sputtering of both under controlled temperature conditions because of the better parametric repeatability obtained. Circuit definition is achieved by a conventional two-stage photolithographic process, first by defining the entire circuit array in nickel-chromium and gold and then by removing gold selectively to form resistors. Sputter etching techniques are used to remove both the nickel-chromium and the gold, thereby avoiding the problems of undercutting associated with wet chemical etching.

The back of each substrate is also sputtered with nickel-chromium, nickel and gold to enable the thin film substrate to be soldered down in its assembly package. Add-on components, including diodes, transistors and integrated circuits, are frequently attached as gold plated beam lead devices. Thermocompression ball and wedge bonding is employed to bond gold wires to the thin film conductors, thereby achieving gold-to-gold attachment and avoiding the formation of undesirable intermetallic compounds during the bonding operation or in subsequent operation in service.

\section{Gold-Aluminium Interconnections}

In a paper by D. W. Bushmire of Sandia Laboratories, Albuquerque, New Mexico on "Resistance Increases in Gold-Aluminium Interconnections with
Time and Temperature" the author explained that recent hybrid applications within his company involved the use of CMOS devices that were not available in beam lead form, and that since these devices had an aluminium metallisation the preferred gold-to-gold interconnect system could not be employed.

The use of a gold-aluminium interconnect thus becomes necessary, either at the chip if gold wire is used, or at the substrate if aluminium wire is used, the latter being selected to avoid intermetallic formation at the chip. Earlier work by the author had shown that a 1 per cent silicon-aluminium alloy wire on chromium-gold thin film showed little degradation of bond strength, but other work carried out at Honeywell had indicated that a significant increase in resistance could occur under temperature ageing conditions and might lead to problems in circuit performance.

In the investigation reported, two thin film systems on alumina substrates, chromium-gold and titanium-palladium-gold, were studied with aluminium wire connections made by ultrasonic bonding. Significant increases in the resistance of the goldaluminium bonds were measured after ageing at intervals of $50^{\circ}$ between $150^{\circ}$ and $300^{\circ} \mathrm{C}$ for periods ranging up to 400 hours. Significant increases in the resistance of the gold-aluminium bonds were found after ageing at these temperatures, but the rate of change of resistance for chromium-gold thin films showed a different behaviour from that of titaniumpalladium-gold. The mechanism of the changes that occurred-without change in mechanical strengthwas not fully explained, although the possibility of more than one mechanism creating the resistance change is suggested by the shape of the curves for resistance against time at a given temperature. 


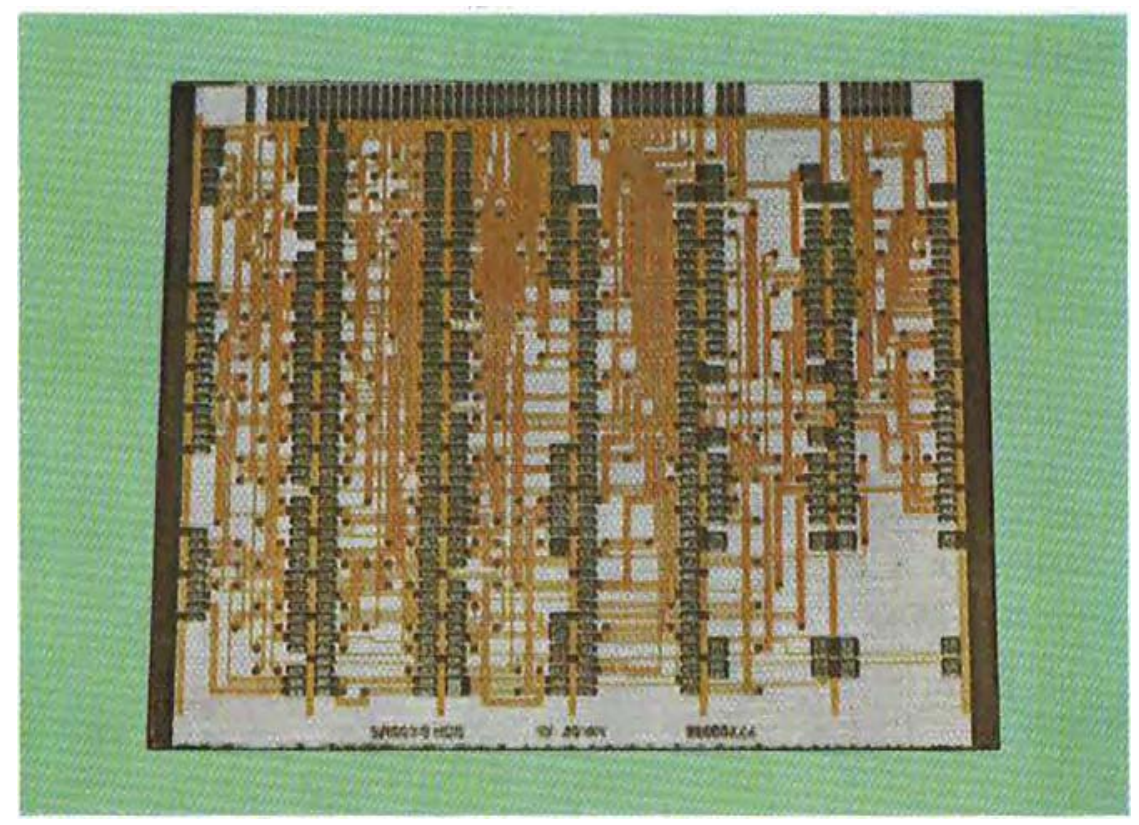

A thick film multilayer circuit, comprising three screen printed gold conductor planes on an alumina substrate, designed and manufactured by Lucas Aerospace, for use in fuel control systems for aircraft jet engines. Further demands on circuit packing density have necessitated the development of five conductor level multilayer circuits, gold being used for all but the uppermost layer, which is in platinum-gold

The author concludes that, if changes in interconnect resistance are likely to have an adverse effect on circuit performance, then the use of a goldaluminium interconnect is not to be recommended in cases where prolonged exposure to temperatures above $150^{\circ} \mathrm{C}$ are involved. Where this is unavoidable a gold-to-gold system should be employed.

\section{Thick Film Multilayer Assemblies}

A paper on "Development and Production Aspects of Thick Film Multilayer Assemblies" by David T. Wall of Lucas Aerospace included a description of typical circuit fabrication techniques used by that company over the past seven years in avionic systems. Thirty different types have been manufactured in production quantities with complexity ranging from two to five conductor levels. Gold is used as the screen-printable material for each conductor level except the uppermost, where platinum-gold is preferred for the component attachment pads because of its good adhesion, resistance to solder leaching and low rate of joint degradation in adverse environments. Electrical conduction between conductor planes is made by filling the windows or vias left in the otherwise blanket glass layers in the multilayer structure with thick film gold paste in a separate screen printing operation.

Compared to a multilayer printed circuit, a multilayer thick film with an equal number of conductor planes has considerably fewer stages of fabrication, while many of these stages are inherently less subject to process variations, a good example being the thick film printed via compared to its counterpart the through-plated hole. In general it is considered that thick film multilayers provide a flexible means of packaging integrated circuits and discrete components, this technique offering higher component packing density and better thermal performance than conventional plastic of fibreglass-epoxy multilayer printed circuit boards.

\section{Factors Affecting Reliable Metallisation}

As part of a continuing study of thick film conductors K. B. Bube of RCA Laboratories, David Sarnoff Research Centre at Princeton, New Jersey, presented a paper on "The Influence of Compositional and Morphological Factors upon Thick Film Metallisation Properties". The effects of processing changes on adhesion and on electrical conductivity had been covered in earlier papers; this report dealt with the factors influencing the bondability of wire-bonded, beam lead bonded and reflow-soldered semiconductor devices to thick film circuits, with some reference to reports of poor bond reliability with certain commercial thick film compositions.

Commercial thick film preparations were classified according to whether the paste binder contained frit, frit plus copper oxide, or copper oxide only. The effects on the strengths of both gold and aluminium ultrasonic wire bonds to layered and conventional gold thick films, after thermal ageing in nitrogen at $400^{\circ} \mathrm{C}$, were tabulated. Because bondability was found to be retarded by the presence of glass frit in pastes consisting of homogeneous mixtures of metal and glass powders, two "model" inks were formulated, one frit based and one metal-based. Careful optimisation of thickness, firing time and temperature produced a layered structure consisting of a predominantly sintered metal-rich layer on top of a 
bluish hue for $\mathrm{AuGa}_{2}$. It is interesting that the energies for the respective minima and maxima in the reflectivity curves are quite similar for the two compounds, $\mathrm{AuIn}_{2}$ and $\mathrm{AuGa}_{2}$. The distinct difference in the intensity of their colouration is to be attributed to the fact that the differences in reflectivity for the various regions of the visible spectrum are less strongly pronounced with $\mathrm{AuGa}_{2}$ than with $\mathrm{AuIn}_{2}$. This, in turn, may be taken as an indication that the densities of state for the energy bands involved in the transition described above differ considerably for these two alloys.

\section{References}

1 W. Köster and R. Stahl, Z. Metallkunde, 1967, 58, (11), 768

$2 \mathrm{H}$. Fukutani and O. Sueoka in "Optical Properties and Electronic Structure of Metals and Alloys", Edited by F. Abelès, North Holland Publ. Comp., Amsterdam, 1966, p. 565

3 K. E. Saeger and J. Rodies, Metall, 1976, 30, (7), 641

4 J. Friedel, Can. F. Phys., 1956, 34, (12A), 1190; Suppl. Nuovo Cim. Bologna, 1958, 7, 287; 7. Phys. Radium, 1962, 23, (10), 693

5 F. Abelès, $\mathcal{F}$. Phys. Radium, 1962, 23, (10), 677

6 F. Abelès in "Optical Properties and Electronic Structure of Metals and Alloys", Edited by F. Abelès, North Holland Publ. Comp., Amsterdam, 1966, p. 553

7 A. C. Switendick and A. Narath, Phys. Rev. Letters, 1969, 22, (26), 1423 